\title{
FAKTOR-FAKTOR YANG MEMPENGARUHI KEGAGALAN PENGOBATAN PASIEN TB PARU DI PUSKESMAS KOTA BANDAR LAMPUNG TAHUN 2018
}

\author{
Fransisca Tarida Yuniar Sinaga 1, Hernowo Anggoro Wasono2, Debi Arivo3, Rhadila Anjani4
}

1Departemen Pulmonologi, Fakultas Kedokteran, Universitas Malahayati

2Departemen Kedokteran Keluarga, Fakultas Kedokteran, Universitas Malahayati

3Departemen Mikrobiologi, Fakultas Kedokteran, Universitas Malahayati

4 Program Studi Kedokteran, Fakultas Kedokteran, Universitas Malahayati

\begin{abstract}
Factors That Affect The Failure Of Lung TB Patients In Public Health Center Bandar Lampung City, 2018. The discovery of new cases of smear $(+) T B$, all TB cases, and Case Notification Numbers (CNR) per 100,000 population in Lampung Province in 2017 amounted to 4.195 cases consisting of 2.587 cases in men and 1.608 cases in women, and CNR in all TB cases $51 \%$. The survey results in the Bandar Lampung City Health Center area get the increase of pulmonary TB cases in 2015,2016,2017 and 2018 with results of $125,138,142$ and 157 cases respectively diagnosed with pulmonary TB. This study was to determine factors the failure of pulmonary TB treatment patients. This study was quantitative research using analytical survey design with case control approach. The population were 63 patient of pulmonary TB who failed the treatment. The data analysis technique using Chi Square statistical tests. There was a correlation between smoking and treatment failure of pulmonary TB patients ( $p$-value $0,000<a 0,05$ ). OR: 4,180 . There was a correlation between preventive behavior and treatment failure of pulmonary TB patients ( $p$ value $0,000<a 0,05)$. OR: 4,267. There was a correlation between supervisors taking medication and treatment failure of pulmonary TB patients ( $p$-value $0.011<a 0.05)$. OR: 2,750. There was an environmental correlation with treatment failure of pulmonary TB patients ( $p$-value $0.004<a$ 0.05). OR: 3,088. There was a correlation among smoking, preventive behavior, supervisor taking drugs and environment with failure of pulmonary TB treatment.
\end{abstract}

Keywords: Treatment Failure, Pulmonary TB.

\begin{abstract}
Abstrak: Faktor-Faktor yang Mempengaruhi Kegagalan Pengobatan Pasien TB Paru di Puskesmas Kota Bandar Lampung Tahun 2018. Penemuan kasus baru TB BTA $(+)$, seluruh kasus TB, dan Case Notification Rate (CNR) per 100.000 penduduk di Provinsi Lampung pada tahun 2017 sebesar 4.195 kasus terdiri dari 2.587 kasus pada laki-laki dan 1.608 kasus pada perempuan, dan CNR seluruh kasus TB sebesar $51 \%$. Hasil survei di wilayah Puskesmas Kota Bandar Lampung ditemukan peningkatan kasus TB paru pada tahun 2015,2016,2017, dan 2018 dengan hasil masing-masing 125,138,142, dan 157 kasus yang terdiagnosa TB paru. Tujuan penelitian ini untuk mengetahui faktor-faktor yang mempengaruhi kegagalan pengobatan pasien TB paru di Puskesmas Kota Bandar Lampung Tahun 2018. Jenis penelitian kuantitatif, rancangan survey analitik dengan pendekatan case control. Populasi seluruh pasien TB paru gagal pengobatan sebanyak 63 pasien dengan teknik total sampling. Pengambilan data menggunakan lembar kuesioner. Teknik analisis data menggunakan uji statistik Chi Square. Ada hubungan merokok dengan kegagalan pengobatan pasien TB paru ( $\mathrm{p}$-value 0,000 <a 0,05). OR: 4,180. Ada hubungan perilaku pencegahan dengan kegagalan pengobatan pasien TB paru ( $p$-value 0,000<a 0,05).OR: 4,267. Ada hubungan pengawas minum obat dengan kegagalan pengobatan pasien TB paru ( $\mathrm{p}$-value $0,011<a$ 0,05). OR: 2,750. Ada hubungan lingkungan dengan kegagalan pengobatan pasien TB paru, diperoleh ( $\mathrm{p}$-value 0,004 <a 0,05). OR: 3,088. Ada hubungan merokok, perilaku pencegahan, pengawas minum obat dan lingkungan dengan kegagalan pengobatan TB paru.
\end{abstract}


Kata Kunci : Kegagalan Pengobatan, TB paru

\section{PENDAHULUAN}

Tuberkulosis (TB) merupakan penyakit menular langsung yang disebabkan oleh bakteri Mycobacterium tuberculosis. Gejala utama adalah batuk selama 2 minggu atau lebih, batuk disertai dengan gejala tambahan yaitu dahak, dahak bercampur darah, sesak nafas, badan lemas, nafsu makan menurun, berat badan menurun, malaise, berkeringat malam hari tanpa kegiatan fisik, demam lebih dari 1 bulan (Kemenkes RI, 2016).

World Health Organization (WHO) menargetkan untuk menurunkan kematian akibat TB sebesar $90 \%$ pada tahun 2030 dibandingkan dengan tahun 2014, tahun 2015 diperkirakan terdapat 10,4 juta kasus baru tuberkulosis atau 142 kasus/100.000 populasi, dengan 480.000 kasus Multi Drug Resistant. Indonesia merupakan negara dengan jumlah kasus baru terbanyak kedua di dunia setelah India. Sebesar 60\% kasus baru terjadi di 6 negara yaitu India, Indonesia, China, Nigeria, Pakistan dan Afrika Selatan (Kemenkes, RI, 2016).

Angka notifikasi kasus Basil Tahan Asam (BTA) pada tahun 2017 di Indonesia sebesar 138 per 100.000 penduduk. Angka keberhasilan pengobatan merupakan jumlah semua kasus TB yang sembuh (cure) dan pengobatan lengkap diantara semua kasus TB yang diobati dan dilaporkan. Tahun 2017 angka keberhasilan pengobatan semua kasus TB sebesar 77,86\%. Angka kesembuhan semua kasus yang harus dicapai minimal $85 \%$ sedangkan angka keberhasilan pengobatan semua kasus minimal 90\% angka keberhasilan pengobatan kasus TB BTA (+) di Provinsi Lampung sebesar $72,52 \%$ masih dibawah target $90 \%$ (Kemenkes, RI, 2016).

Penemuan kasus baru TB BTA $(+)$, seluruh kasus TB, dan case notification rate (CNR) per 100.000 penduduk di Provinsi Lampung pada tahun 2017 sebesar 4.195 kasus terdiri dari 2.587 kasus pada laki-laki dan 1.608 kasus pada perempuan, dan CNR seluruh kasus TB sebesar $51 \%$. Sedangkan cakupan TB BTA (+) sembuh sebesar 97,16\%, dan angka keberhasilan pengobatan (success rate) sebesar 75,52\%. Hasil survei di wilayah Puskesmas Kota Bandar Lampung ditemukan peningkatan kasus TB paru pada tahun 2015,2016,2017, dan 2018 dengan hasil masing - masing 125,138,142, dan 157 yang terdiagnosa TB paru (Profil Dinas Kesehatan Provinsi Lampung, 2018).

Studi yang dilakukan oleh Shofiya \& Sari (2015), mengenai hubungan keteraturan minum obat dengan kegagalan konversi pasien TB Paru BTA (+) pada akhir pengobatan fase intensif kategori 1 di Kota Surabaya tahun 2015 menunjukkan bahwa pada kelompok kegagalan konversi pasien TB Paru BTA (+) pada akhir pengobatan fase intensif kategori 1 sebagian besar pasien teratur minum obat yaitu sebesar 70,4\%. Penelitian yang dilakukan Yuniar, dkk (2017) pengaruh peran PMO dan dukungan keluarga terhadap kepatuhan minum obat. Hasil penelitian Terdapat hubungan faktor PMO dengan Kepatuhan Minum obat TB di Daerah Wilayah Puskesmas Sempor 1 Kebumen dengan nilai ( $p$-value $=0,004<a$ $0,05)$.

\section{METODE}

Jenis penelitian yang digunakan dalam penelitian ini adalah kuantitatif analitik yaitu jenis penelitian yang mencoba mengetahui mengapa masalah kesehatan tersebut bisa terjadi kemudian melakukan analisis hubungannya (Riyanto, 2011). Pada penelitian ini untuk mengetahui gambaran distribusi frekuensi merokok, perilaku pencegahan, pengawas minum obat (PMO), dan Lingkungan apakah ada hubungan variabel independen terhadap variabel dependen. Rancangan penelitian yang digunakan analitik dengan pendekatan case control yaitu penelitian 
yang mempelajari hubungan antara faktor risiko (independen) dan faktor efek (dependen) dimana pengukuran variabel bebas dan variabel terikat sekaligus pada waktu yang sama (Riyanto, 2011).

\section{HASIL}

Tabel 1 Distribusi Frekuensi Karakteristik Usia Pasien TB Paru Kasus Gagal Pengobatan di Puskesmas Kota Bandar Lampung Tahun 2018

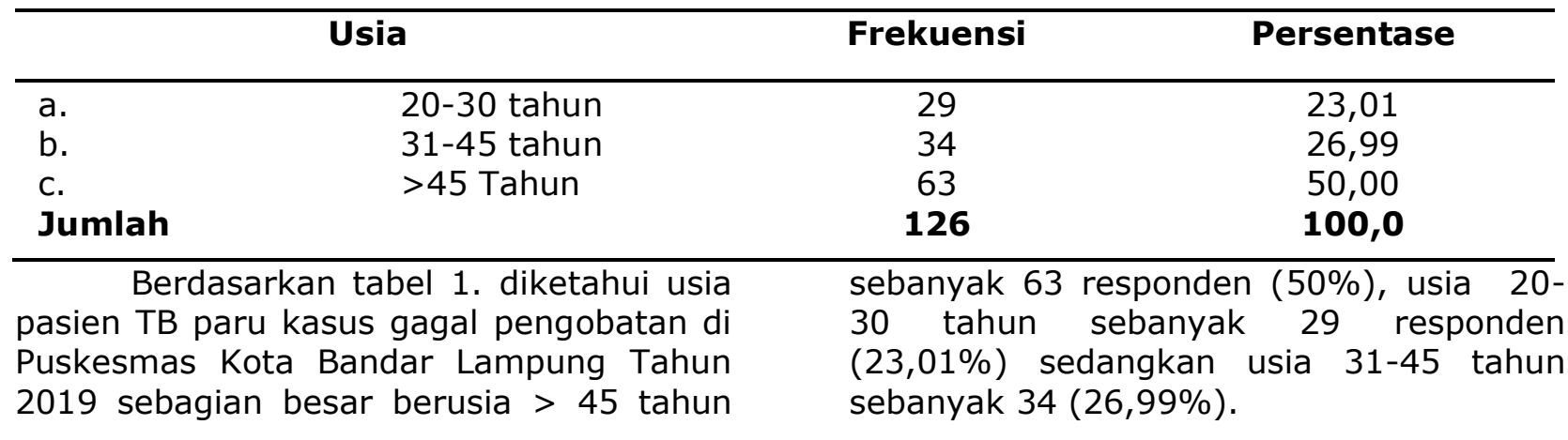

Tabel 2 Distribusi Frekuensi Karakteristik Jenis Kelamin Pasien TB Paru Kasus Gagal Pengobatan di Puskesmas Kota Bandar Lampung Tahun 2018

\begin{tabular}{lccc}
\hline & Jenis Kelamin & Frekuensi & Persentase \\
\hline a. & Laki-laki & 82 & 65,08 \\
b. & Perempuan & 44 & 34,92 \\
Jumlah & & $\mathbf{1 2 6}$ & $\mathbf{1 0 0 , 0}$ \\
\hline \multicolumn{2}{c}{ Berdasarkan tabel 2. diketahui jenis } & laki sebanyak 82 responden (65,08\%) dan \\
kelamin pasien TB paru kasus gagal & jenis kelamin perempuan sebanyak 44 \\
pengobatan di Puskesmas Kota Bandar & responden (34,92\%).
\end{tabular}

Lampung Tahun 2019 sebagian besar laki-

Tabel 3 Distribusi Frekuensi Karakteristik Pasien TB Paru Kasus Gagal Pengobatan di Puskesmas Kota Bandar Lampung Tahun 2018

\begin{tabular}{llll}
\hline Kelompok TB paru kasus gagal & Frekuensi & Persentase \\
\hline a. & Kasus Putus Obat & 18 & 28,57 \\
b. Kasus Kambuh & 34 & 53,96 \\
c. & Kasus Gagal Pengobatan & 11 & 17,46
\end{tabular}

Jumlah

Berdasarkan tabel 3. diketahui karakteristik pasien TB paru kasus gagal pengobatan di Puskesmas Kota Bandar Lampung Tahun 2019 sebagian besar kasus kambuh sebanyak 34 responden
100,0

$(53,96 \%)$, kasus putus obat sebanyak 18 responden $(28,57 \%)$ dan kasus gagal pengobatan sebanyak 11 responden $(17,46 \%)$ 


\section{Analisis Bivariat}

Tabel 4 Analisa Hubungan Merokok dengan Kegagalan Pengobatan Pasien TB Paru di Puskesmas Kota Bandar Lampung Tahun 2018

\begin{tabular}{|c|c|c|c|c|c|c|c|c|}
\hline \multirow[t]{3}{*}{ Merokok } & \multicolumn{4}{|c|}{$\begin{array}{c}\text { Kegagalan } \\
\text { Pengobatan Pasien } \\
\text { TB } \\
\end{array}$} & \multirow{2}{*}{\multicolumn{2}{|c|}{ Total }} & \multirow[t]{3}{*}{ p-value } & \multirow{3}{*}{$\begin{array}{c}\text { OR } \\
(95 \% \mathrm{CI})\end{array}$} \\
\hline & \multicolumn{2}{|c|}{ Kasus } & \multicolumn{2}{|c|}{ Kontrol } & & & & \\
\hline & $\mathrm{n}$ & $\%$ & $n$ & $\%$ & $n$ & $\%$ & & \\
\hline Merokok & $\begin{array}{l}3 \\
7\end{array}$ & 69,8 & $\begin{array}{l}1 \\
6\end{array}$ & 30,2 & 53 & 100 & 0,000 & 4,180 \\
\hline Tidak merokok & $\begin{array}{l}2 \\
6\end{array}$ & 35,6 & $\begin{array}{l}4 \\
7\end{array}$ & 64,4 & 73 & 100 & & $(1,960-8,914)$ \\
\hline
\end{tabular}

Berdasarkan tabel 4 diketahui bahwa dari 63 responden pada kelompok kasus yang merokok sebanyak 37 responden $(69,8 \%)$, dan 26 responden $(35,6 \%)$ dengan kategori tidak merokok. Sedangkan pada kelompok kontrol dari 63 responden terdapat 16 responden $(30,2 \%)$ yang merokok, dan 47 responden $(64,4 \%)$ kategori tidak merokok. Hasil uji statistik $(p-$ value $=0,000)$ lebih kecil dari nilai alpha ( $\alpha=0,05$ ) berarti ada hubungan yang bermakna antara merokok dengan kegagalan pengobatan pasien TB paru di Puskesmas Kota Bandar Lampung Tahun 2019. Dari hasil analisis diperoleh nilai OR: 4,180. Artinya responden yang merokok berisiko 4 kali terjadi kegagalan pengobatan dibandingkan dengan responden yang tidak merokok.

Tabel 5 Analisa Hubungan Perilaku Pencegahan dengan Kegagalan Pengobatan Pasien TB Paru di Puskesmas Kota Bandar Lampung Tahun 2018

\begin{tabular}{|c|c|c|c|c|c|c|c|c|}
\hline \multirow{3}{*}{ Perilaku Pencegahan } & \multicolumn{4}{|c|}{ Kejadian TB paru } & \multirow{2}{*}{\multicolumn{2}{|c|}{ Total }} & \multirow{3}{*}{$\begin{array}{l}\mathrm{p}- \\
\text { valu } \\
e\end{array}$} & \multirow{3}{*}{$\begin{array}{c}\text { OR } \\
(95 \% \mathrm{CI})\end{array}$} \\
\hline & \multicolumn{2}{|c|}{ Kasus } & \multicolumn{2}{|c|}{ Kontrol } & & & & \\
\hline & $\mathrm{n}$ & $\%$ & $\mathrm{n}$ & $\%$ & $\mathrm{n}$ & $\%$ & & \\
\hline \multirow{2}{*}{$\begin{array}{l}\text { Perilaku kurang baik } \\
\text { Perilaku baik }\end{array}$} & 36 & 70,6 & 15 & 29,4 & 51 & 100 & \multirow{2}{*}{0,000} & \multirow{2}{*}{$\begin{array}{c}4,267 \\
(1,986-9,168)\end{array}$} \\
\hline & 27 & 36,0 & 48 & 64,0 & 75 & 100 & & \\
\hline
\end{tabular}

Berdasarkan tabel 5. diketahui bahwa dari 63 responden pada kelompok kasus yang berperilaku kurang baik sebanyak 36 responden $(70,6 \%)$, dan 27 responden $(36,0 \%)$ berperilaku baik. Sedangkan pada kelompok kontrol dari 63 responden terdapat 15 responden $(29,4 \%)$ yang berperilaku baik, dan 48 responden $(64,0 \%)$ yang berperilaku kurang baik. Hasil uji statistik ( $p$-value $=0,000)$ lebih kecil dari nilai alpha $(\alpha=0,05)$ berarti ada hubungan yang bermakna antara perilaku pencegahan TB paru dengan kegagalan pengobatan pasien TB paru di Puskesmas Kota Bandar Lampung Tahun 2019. Dari hasil analisis diperoleh nilai OR: 4,267. Artinya responden yang perilaku pencegahan TB parukurang baik berisiko 4 kali terjadi kegagalan pengobatan dibandingkan dengan perilaku baik. 
Tabel 6 Analisa Hubungan Pengawas Minum Obat dengan Kegagalan Pengobatan Pasien TB Paru di Puskesmas Kota Bandar Lampung Tahun 2018

\begin{tabular}{|c|c|c|c|c|c|c|c|c|}
\hline \multirow{3}{*}{$\begin{array}{c}\text { Pengawas Minum } \\
\text { Obat }\end{array}$} & \multicolumn{4}{|c|}{ Kejadian TB paru } & \multirow{2}{*}{\multicolumn{2}{|c|}{ Total }} & \multirow{3}{*}{$\mathrm{p}$-value } & \multirow{3}{*}{$\begin{array}{c}\text { OR } \\
(95 \% \mathrm{CI})\end{array}$} \\
\hline & \multicolumn{2}{|c|}{ Kasus } & \multicolumn{2}{|c|}{ Kontrol } & & & & \\
\hline & $\mathrm{n}$ & $\%$ & $\mathrm{n}$ & $\%$ & $\mathrm{n}$ & $\%$ & & \\
\hline \multirow{2}{*}{$\begin{array}{l}\text { Kurang baik } \\
\text { Baik }\end{array}$} & 33 & 64,7 & 18 & 35,3 & 51 & 100 & \multirow{2}{*}{0,011} & \multirow{2}{*}{$\begin{array}{c}2,750 \\
(1,316-5,747)\end{array}$} \\
\hline & 30 & 40,0 & 45 & 60,0 & 75 & 100 & & \\
\hline
\end{tabular}

Berdasarkan tabel 6. diketahui bahwa dari 63 responden pada kelompok kasus dengan pengawas minum obat kurang baik sebanyak 33 responden $(64,7 \%)$, dan 30 responden $(40,0 \%)$ dengan pengawas minum obat kategori baik. Sedangkan pada kelompok kontrol dari 63 responden terdapat 18 responden $(35,3 \%)$ dengan pengawas minum obat kurang baik, dan45 responden $(60,0 \%)$ dengan pengawas minum obat kategori baik. Hasil uji statistik ( $p$-value $=0,011$ ) lebih kecil dari nilai alpha $(\alpha=0,05)$ berarti ada hubungan yang bermakna antara pengawas minum obat dengan kegagalan pengobatan pasien TB paru di Puskesmas Kota Bandar Lampung Tahun 2019. Dari hasil analisis diperoleh nilai OR: 2,750. Artinya responden dengan pengawas minum obat kurang baik berisiko 2 kali terjadi kegagalan pengobatan dibandingkan dengan pengawas minum obat kategori baik.

Tabel 7 Analisa Hubungan Lingkungan dengan Kegagalan Pengobatan Pasien TB Paru di Puskesmas Kota Bandar Lampung Tahun 2018

\begin{tabular}{|c|c|c|c|c|c|c|c|c|}
\hline \multirow{3}{*}{ Lingkungan } & \multicolumn{4}{|c|}{ Kejadian TB paru } & \multirow{2}{*}{\multicolumn{2}{|c|}{ Total }} & \multirow{3}{*}{$\mathrm{p}$-value } & \multirow{3}{*}{$\begin{array}{c}\text { OR } \\
(95 \% \mathrm{CI})\end{array}$} \\
\hline & \multicolumn{2}{|c|}{ Kasus } & \multicolumn{2}{|c|}{ Kontrol } & & & & \\
\hline & $\mathrm{n}$ & $\%$ & $n$ & $\%$ & $\mathrm{n}$ & $\%$ & & \\
\hline \multirow{2}{*}{$\begin{array}{l}\text { Kurang baik } \\
\text { Baik }\end{array}$} & 36 & 65,5 & 19 & 34,5 & 55 & 100 & \multirow{2}{*}{0,004} & \multirow{2}{*}{$\begin{array}{c}3,088 \\
(1,482-6,432)\end{array}$} \\
\hline & 27 & 38,0 & 44 & 62,0 & 71 & 100 & & \\
\hline
\end{tabular}

Berdasarkan tabel 7. diketahui bahwa dari 63 responden pada kelompok kasus dengan lingkungan kurang baik sebanyak 36 responden (65,5\%), dan 27 responden $(38,0 \%)$ dengan lingkungan kategori baik. Sedangkan pada kelompok kontrol dari 63 responden terdapat 19 responden $(34,5 \%)$ dengan lingkungan kurang baik, dan 44 responden $(62,0 \%)$ dengan lingkungan kategori baik. Hasil uji statistik $(p-$ value $=0,004)$ lebih kecil dari nilai alpha $(\alpha=0,05)$ berarti ada hubungan yang bermakna antara lingkungan dengan kegagalan pengobatan pasien TB paru di Puskesmas Kota Bandar Lampung Tahun 2019. Dari hasil analisis diperoleh nilai OR: 3,088. Artinya responden dengan lingkungan kurang baik berisiko 3 kali terjadi kegagalan pengobatan dibandingkan dengan lingkungan kategori baik. 


\section{PEMBAHASAN}

\section{Hubungan Kegagalan Pengobatan Pasien TB Paru}

Hasil studi menunjukan ada hubungan yang bermakna antara merokok dengan kegagalan pengobatan pasien TB paru di Puskesmas Kota Bandar Lampung Tahun 2019 ( $p$-value $=0,000)$. Responden yang merokok berisiko 4 kali terjadi kegagalan pengobatan dibandingkan dengan responden yang tidak merokok (OR: 4,180). Hal ini sejalan dengan hasil studi sebelumnya tentang hubungan kebiasaan merokok dengan kejadian tuberkulosis paru di Puskesmas Siloam Kecamatan Tamako Kabupaten Kepulauan Sangihe diperoleh hasil ( $p$-value $=0,01 a=0,05$ ) bahwa ada hubungan bermakna antara kebiasaan merokok dengan kejadian tuberkulosis paru (Lalombo, dkk, 2015).

Dari hasil studi Romlah (2015). Yang menunjukkan bahwa ada hubungan yang signifikan antara pernah merokok dengan kejadian TB Paru dengan besar risiko 3,44 kali lebih besar pada kasus dibanding pada kontrol. Sejalan dengan hal ini studi Sarwani \& Nurlaela (2012) juga menunjukkan ada hubungan yang signifikan antara merokok dengan kejadian Tuberkulosis Paru ( $\mathrm{p}$-value $=0,022)$.

Hal ini juga berbeda dengan studi Soetioso (2014) yang menunjukkan tidak didapatkan hubungan yang signifikan antara kebiasaan merokok dengan derajat positif dari hasil pemeriksaan sputum BTA $(+)$. Bahwa faktor risiko kejadian Tuberkulosis Paru di Kecamatan Baturetno Kabupaten Wonogiri dengan hasil analisis ( $p$-value $=0,627)$.

Orang yang merokok akan lebih berisiko terkena tuberkulosis disebabkan karena merokok dapat menggangu efektivitas sebagian mekanisme pertahanan respirasi. Merokok dalam rumah merupakan factor risiko untuk terkena kejadian TB paru BTA $(+)$, polusi udara dalam ruangan dari asap rokok dapat meningkatkan risiko terinfeksi bakteri M. tuberculosis (Sejati dkk,2015).
Hal ini juga sesuai hasil studi yang menyatakan bahwa merokok dapat merusak saluran pernafasan yang dapat memudahkan invasi bakteri TB dalam jangka panjang yaitu 10-20 tahun. Pengaruh risiko merokok terhadap TB paru adalah bila merokok 1-10 batang per hari meningkatkan risiko 15 kali, bila merokok 20-30 batang per hari meningkatkan risiko 40-50 kali dan bila merokok 40-50 batang per hari meningkatkan risiko 70-80 kali. Penghentian kebiasaan merokok, baru akan menunjukkan penurunan risiko setelah 3 tahun dan akan menunjukkan risiko yang sama dengan bukan perokok setelah 10-13 tahun (Sianturi, 2014).

Proses terjadinya infeksi oleh $M$. tuberculosis biasanya berlangsung secara inhalasi, sehingga TB paru merupakan menifestasi klinis yang paling sering terjadi dibandingkan dengan organ lainya. Penularan penyakit ini sebagian besar berlangsung melalui inhalasi basil yang mengandung droplet nuclei, khususnya yang didapat dari pasien TB paru dengan batuk berdarah atau berdahak yang mengandung Basil Tahan Asam BTA (+) (Sudoyo dkk, 2014).

\section{Hubungan Perilaku Pencegahan TB Paru dengan Kegagalan Pengobatan Pasien TB Paru}

Hasil studi menunjukan ada hubungan yang bermakna antara perilaku pencegahan TB paru dengan kegagalan pengobatan pasien TB paru di Puskesmas Kota Bandar Lampung Tahun 2019 (pvalue $=0,000)$. Responden dengan perilaku pencegahan TB parukurang baik berisiko 4 kali terjadi kegagalan pengobatan dibandingkan dengan perilaku baik (OR: 4,267). Hal ini sejalan dengan hasil studi sebelumnya tentang tentang hubungan keadaan lingkungan dan perilaku pencegahan dengan kejadian TB paru di Puskesmas Hajimena Kabupaten Lampung Selatan Tahun 2016. Hasil penelitian diketahui ada hubungan perilaku pencegahan TB paru dengan kejadian TB 
paru, diperoleh (p-value $0,000<a 0,05)$ (Angelina dkk, 2016).

Perilaku manusia sangat berpengaruh dalam menularkan penyakit menular terutama perilaku yang tidak positif, sehingga lingkungan dapat berubah sedemikian rupa menjadi tempat yang ideal sebagai tempat penularan penyakit.Perilaku penderita TB paru BTA (+) yang tidur bersama-sama dalam satu tempat tidur/kamar dengan istri, suami anak dan anggota keluarga lainnya dapat menularkan penyakit TB paru sebanyak $68 \%$. Selama sakitnya penderita TB paru dengan sputum BTA (+) bisa menularkan berpuluh-puluh orang sampai beratusratus orang tetapi bisa juga hanya 1-2 orang saja atau nihil. Untuk mempertahankan keadaan seimbang atau prevalensi tetap sama. Seorang penderita TB paru dengan BTA (+) hanya perlu menulari 20 orang sehat, dan kemudian diantaranya satu orang akan menjadi pengganti sebagai sumber penularan baru setelah lama menjadi sembuh atau mati (Putra, 2011).

Perilaku manusia pada hakikatnya adalah suatu aktivitas dari manusia itu sendiri. Oleh sebab itu, perilaku manusia itu mempunyai bentangan yang sangat luas, mencakup berjalan, berbicara, bereaksi, berpakaian dan lain sebagainya. Bahkan kegiatan internal (internal activity) seperti berfikir, persepsi dan emosi yang merupakan perilaku manusia (Notoatmodjo, 2012).

Berdasarkan pengolahan data diperoleh hasil bahwa sebagian besar pendidikan responden adalah dengan kategori pendidikan rendah (SD), hasil ini menunjukkan bahwa tingkat pendidikan dasar ini berhubungan dengan pengetahuan yang dimiliki responden tersebut dalam berperilaku pencegahan tuberkulosis paru. Pendidikan adalah proses pengubahan sikap dan tata laku seseorang atau kelompok orang dalam usaha mendewasakan manusia melalui upaya pengajaran dan pelatihan, proses, pembuatan cara mendidik.
Berdasarkan hal tersebut bahwa kurang baiknya perilaku responden tersebut dikarenakan responden tidak mengetahui tentang TB paru seperti pencegahan, penularan serta pengobatan TB paru sehingga berdampak pada kurang baiknya perilaku responden tersebut, selain itu juga hal ini dikarenakan rendahnya pendidikan serta sosial ekonomi yang kurang. Berdasarkan hasil tersebut peneliti berpendapat bahwa perilaku penderita merupakan salah satu faktor yang dapat menyebabkan timbulya masalah penyebaran bakteri Mycobacterium tuberculosis. Namun demikian pengetahuan dan perilaku penderita dalam mencegah agar anggota keluarga tidak tertular berpengaruh besar dalam kesembuhan dan pencegahan penyakit TB paru.

\section{Hubungan Pengawas Minum Obat dengan Kegagalan Pengobatan Pasien TB Paru}

Hasil studi menunjukan ada hubungan yang bermakna antara pengawas minum obat dengan kegagalan pengobatan pasien TB paru di Puskesmas Kota Bandar Lampung Tahun 2019 ( $\mathrm{p}$-value = 0,011). Responden dengan pengawas minum obat kurang baik berisiko 2 kali terjadi kegagalan pengobatan dibandingkan dengan pengawas minum obat kategori baik. OR: 2,750. Hasil penelitian ini didukung dengan hasil studi tentang pengaruh peran PMO dan dukungan keluarga terhadap kepatuhan minum obat. Penelitian ini menggunakan metode analitik dengan rancangan cross sectional dengan teknik analisa bivariat chi square. Hasil penelitian terdapat hubungan yang signifikan antara faktor PMO dengan Kepatuhan Minum obat TB di Daerah Wilayah Puskesmas Sempor 1 Kebumen dengan nilai $(p$-value $=0,004<0,05)$ (Yuniar dkk, 2017).

Hal ini sesuai dengan teori yang dikemukakan Kemenkes RI (2016) yang menyatakan bahwa Salah satu komponen Directly Observed Treatment Shortcourse 
(DOTS) adalah pengobatan paduan OAT jangka pendek dengan pengawasan langsung. Untuk menjamin kepatuhan pengobatan diperlukan seorang pengawas minum obat (PMO). Petugas kesehatan menjelaskan pentingnya pengawasaan menelan obat bagi pasien. Jelaskan bahwa pasien menelan seluruh obat dengan diawasi oleh seorang PMO, untuk memastikan bahwa pasien menelan seluruh obat secara benar, teratur dan sesuai waktu yang ditentukan.

Selanjutnya Kemenkes RI (2016) menyatakan bahwa belum optimalnya penanganan TB Paru diperkirakan terkait dengan beberapa faktor, diantaranya adalah rendahnya dukungan anggota keluarga untuk berperan aktif menjadi PMO (Pengawas Minum Obat) yang berdampak pada rendahnya motivasi pasien untuk disiplin minum obat begitu kondisinya membaik dan menghentikan minum obat begitu merasa sudah sembuh, padahal jika pengobatan teratur penderita dapat mengalami kesembuhan pada fase pengobatan intensif dimana BTA (+) berubah menjadi BTA (-) atau disebut konversi.

Berdasarkan hal tersebut peneliti berpendapat bahwa dukungan anggota keluarga dalam hal ini pengawas minum obat ikut menentukan hasil pengobatan TB. Untuk itu, keluarga juga harus diberikan informasi tentang TB agar terus menerus mampu mendampingi pasien selama pengobatan. Peran serta tugas PMO pada proses penyembuhan penyakit, penderita TB akan memberikan respon dan sikap yang positif untuk minum obat secara teratur demi kesembuhan penyakitnya, dengan minum obat secara rutin penderita TB akan terhidar dari risiko resistensi yaitu gagal menjalankan pengobatan dan akan kembali berobat dari awal pengobatan, sehingga akan membuat jangka waktu pengobatan lebih lama dan dengan terapi pengobatan awal, selain risiko penularan kepada keluarga atau orang terdekat yang sering ditemui penderita.

\section{Hubungan Keadaan Lingkungan Rumah dengan Kejadian TB Paru}

Hasil studi menunjukan ada hubungan yang bermakna antara lingkungan dengan kegagalan pengobatan pasien TB paru di Puskesmas Kota Bandar Lampung Tahun 2019 ( $p$-value $=0,004)$. Responden dengan lingkungan kurang baik berisiko 3 kali terjadi kegagalan pengobatan dibandingkan dengan lingkungan kategori baik (OR: 3,088). Hasil penelitian ini sejalan dengan studi tentang hubungan lingkungan dengan kejadian TB paru pada pasien gangguan pernafasan di wilayah kerja Puskesmas Kupang Kota Bandar Lampung Tahun 2015 Hasil penelitian menunjukan Ada hubungan lingkungan rumah dengan kejadian TB paru, diperoleh (p-value 0,001 < a 0,05) (Bahtiar \& Ibrahim, 2016).

Kesehatan Lingkungan pada hakikatnya adalah suatu kondisi atau keadaan lingkungan yang optimum sehingga berpengaruh positif terhadap terwujudnya status kesehatan yang optimum pula. Ruang lingkup kesehatan lingkungan tersebut antara lain mencakup perumahan. Rumah adalah salah satu persyaratan pokok bagi kehidupan manusia (Notoatmodjo, 2011).

Bakteri penyakit TB paru ditularkan dari penderita ke orang lain melalui udara, bakteri TB paru yang ada di udara terhisap oleh penjamu baru dan masuk keseluruh saluran pernafasan. Dari saluran pernafasan bakteri menyebar ke seluruh tubuh apabila orang yang terinfeksi ini rentan, maka ia akan terkena TB paru. Faktor perilaku yang bisa menyebabkan kejadian TB paru diantaranya adalah Asap didalam rumah, ada anggota keluarga yang menderita TB paru di rumah yang mempunyai kebiasaan kurang baik (tidak menutup mulut pada saat batuk atau bersin dekat anak), kebersihan rumah yang kurang, menggunakan obat nyamuk bakar, membawa anak pada saat memasak (Irianto, 2012).

Hasil studi Yoga (2007) mengatakan bahwa TB dapat menular yang tinggal di 
rumah padat, kurang sinar matahari dan sirkulasinya buruk atau lembab karena bakteri Mycobacterium Tuberculosis akan dapat menetap lama dan berkembang biak tetapi jika banyak udara dan yang terutama sinar matahari dan sirkulasi, ventilasi baik bakteri itu tidak akan bertahan lama sekitar 1-2 jam.

Penularan TB paru dapat terjadi karena terhirupnya percikan udara yang mengandung bakteri tuberkulosis. Bakteri ini dapat menyerang berbagai organ tubuh, seperti paru-paru (sering terjadi) kelenjar getah bening, tulang, sendi, ginjal, hati, atau selaput otak (yang terberat). Infeksi primer terjadi pada saat seseorang terjangkit TB untuk pertama kalinya. Bakteri ini sangat kecil ukurannya sehingga dapat melewati sistem pertahanan mukosillier bronkus dan terus berkembang (Zabaidah dkk, 2013).

Peneliti berasumsi bahwa kondisi pencahayaan merupakan faktor risiko yang cukup signifikan, dengan pencahayaan yang kurang maka perkembangan bakteri TB Paru akan meningkat karena cahaya matahari merupakan salah satu faktor yang dapat membunuh bakteri TB Paru, jika pencahayaan bagus maka penularan dan perkembangbiakan bakteri bisa dicegah. bakteri tuberkulosis dapat mati karena cahaya sinar ultraviolet dari sinar matahari yang masuk ke dalam ruangan. Diutamakan cahaya matahari pagi karena cahaya matahari pagi mengandung sinar ultraviolet yang dapat membunuh bakteri. Pada saat penelitian, studi menemukan lingkungan rumah yang cukup padat dan kumuh sebanyak 40 responden, bahkan ditemukan dalam satu rumah dihuni 2-3 kepala keluarga, kondisi lingkungan terlihat kumuh, tempat pembuangan tidak ada, tidak jarang warga membuang limbah kesungai sehingga mencemari air sungai yang menjadi kotor dan bau. Selain itu pada penderita TB paru rata-rata responden tidak menjaga lingkungan seperti buang ludah sembarangan, alatalat makan tidak dipisah, tidak menggunakan masker bahkan ditemukan anak kecil yang tinggal serumah dengan penderita TB paru. Untuk itu disarankan keluarga agar menjaga kebersihan lingkungan rumah serta membuat ventilasi agar cahaya pagi hari masuk kedalam ruangan, menggunakan genting kaca untuk menambah intensitas cahaya yang masuk kedalam rumah dan disarankan bagi anggota keluarga yang menderita TB paru agar tidak membuang ludah sembarangan, menutup mulut saat batuk dan menggunakan masker serta penataan ruangan agar tidak terlihat sempit. Berdasarkan hal tersebut peneliti berpendapat bahwa lingkungan rumah bukanlah merupakan penyebab langsung terjadinyaTB paru, tetapi keadaan lingkungan rumah mempunyai pengaruh yang positif terjadinya TB paru.

Notoadmojo (2012) mengatakan bahwa perilaku adalah merupakan respon atau reaksi seseorang terhadap stimulus (rangsangan dari luar). Perilaku dalam penelitian ini adalah tindakan atau kebiasaan yang biasa dilakukan oleh responden terhadap pencegahan penularan infeksi tersebut. Berdasarkan penelitian yang telah dilakukan pasien TB paru BTA (+) dengan sanitasi lingkungan baik sebanyak 8 orang $(19.5 \%)$ dan sanitasi lingkungan kurang baik sebanyak 2 orang $(4,87 \%)$. Begitu juga pasien TB paru BTA (-) dengan saitasi lingkungan baik sebanyak 16 orang (39\%) dan kurang baik sebanyak 15 orang (36,5\%). Dengan hasil chi-square 0,008, yang artinya ada hubungan yang signifikan antara pasien TB paru dengan sanitasi lingkungan.

\section{KESIMPULAN}

Berdasarkan hasil penlitian dengan judul "faktor-faktor yang mempengaruhi kegagalan pengobatan pasien TB paru di puskesmas kota Bandar lampung" dapat ditarik kesimpulan sebagai berikut:

1. Distribusi frekuensi karakteristik pasien TB paru kasus gagal pengobatan di Puskesmas Kota Bandar Lampung Tahun 2018, usia responden sebagian besar berusia > 45 tahun sebanyak 63 
responden $(50 \%)$, jenis kelamin responden sebagian besar laki-laki sebanyak 82 responden $(65,08 \%)$.

2. Distribusi frekuensi merokok pada pasien TB paru kasus gagal pengobatan di Puskesmas Kota Bandar LampungTahun 2018, pada kelompok kasus sebagian besar dengan kategori merokok sebanyak 37 responden $(58,73 \%)$, sedangkan pada kelompok kontrol dengan kategori tidak merokok sebanyak 47 responden $(74,60 \%)$.

3. Distribusi frekuensi perilaku pencegahan kejadian TB paru kasus gagal pengobatan di Puskesmas Kota Bandar Lampung Tahun 2018, pada kelompok kasus sebagian besar dengan kategori kurang baik sebanyak 36 responden $(57,14 \%)$, sedangkan pada kelompok kontrol dengan kategori baik sebanyak 48 responden $(76,2 \%)$.

4. Distribusi frekuensi pengawas minum obat pada pasien TB paru kasus gagal pengobatan di Puskesmas Kota Bandar Lampung Tahun 2018. pada kelompok kasus sebagian besar dengan kategori kurang baik sebanyak 33 responden $(52,4 \%)$, sedangkan pada kelompok kontrol dengan kategori baik sebanyak 45 responden $(71,4 \%)$.

5. Distribusi frekuensi keadaan lingkungan pada pasien TB paru kasus gagal pengobatan di Puskesmas Kota Bandar Lampung Tahun 2018, pada kelompok kasus sebagian besar dengan kategori lingkungan rumah kurang baik sebanyak 36 responden $(57,1 \%)$, sedangkan sedangkan pada kelompok kontrol dengan kategori baik sebanyak 44 responden $(69,8 \%)$.

6. Ada hubungan merokok dengan kegagalan pengobatan pasien TB paru di Puskesmas Kota Bandar Lampung Tahun 2018, diperoleh ( $p$-value 0,000<a 0,05). OR: 4,180.

7. Ada hubungan perilaku pencegahan dengan kegagalan pengobatan pasien TB paru di Puskesmas Kota Bandar Lampung Tahun 2018, diperoleh ( $p$ value $0,000<\mathrm{a} 0,05)$. OR: 4,267.
8. Ada hubungan pengawas minum obat dengan kegagalan pengobatan pasien TB paru di Puskesmas Kota Bandar Lampung Tahun 2018, diperoleh ( $p$ value $0,011<$ a 0,05). OR: 2,750.

9. Ada hubungan lingkungan dengan kegagalan pengobatan pasien TB paru di Puskesmas Kota Bandar Lampung Tahun 2018, diperoleh ( $p$-value 0,004< a 0,05$)$. OR: 3,088 .

\section{DAFTAR PUSTAKA}

Angelina., Hidayat., Retnoningrum. (2016). Hubungan Keadaan Lingkungan Dan Perilaku Pencegahan Dengan Kejadian TB Paru Di Puskesmas Hajimena Kabupaten Lampung Selatan. Jurnal Dunia Kesmas 6 (3); 141.

Bahtiar, I., \& Ibrahim, E. (2012). Hubungan Prilaku dan Kondisi Lingkungan Fisik Rumah dengan Kejadian TB Paru di Kota Bima Provinsi NTB. Jurnal Media Kesehatan Indonesia 4 (3); 132133.

Kementrian Kesehatan Republik Indonesia. [KemenkesRI]. (2016). Profil Kesehatan Indonesia Tahun 2015. Jakara: Kementerian Kesehatan Republik Indonesia.

KeMenKes, R. I. (2016). Pedoman Nasional Pengendalian Tuberkulosis. Permenkes Nomor 67 Tahun 2016. Jakarta: Kementerian Kesehatan Republik Indonesia. 78-86, 112113.

Irianto, K. (2012). Anatomi dan fisiologi. Bandung: Alfabeta, 3 (3); 170.

Lalombo, A. Y., Palandeng, H., \& Kallo, V. (2015). Hubungan Kebiasaan Merokok Dengan Kejadian Tuberkulosis Paru di Puskesmas Siloam Kecamatan Tamako Kabupaten Kepulauan Sangiahe. Jurnal keperawatan, 3(2); 154. 
Notoatmodjo, S. (2011). Kesehatan Masyarakat. Ilmu Dan Seni. Jakarta: Penerbit PT. Rineka Cipta. Hal 167.

Putra. (2011). Hubungan Prilaku dan Kondisi Sanitasi Rumah dengan Kejadian TB paru Di Kota Solok Tahun 2011. Program Studi IImu Kesehatan Masyarakat Fakultas Kedokteran Universitas Andalas. Hal 189.

World Health Organization [WHO]. (2015). Global Tuberculosis Report. Diakses pada tanggal 14 Januari 2016, dari: http://www.who.int/tb/publications /global_report/en/

Riyanto. (2011). Aplikasi Metodelogi Penelitian Kesehatan. Yogyakarta: Nuha Medika.

Hal 89.

Romlah, L. (2015). Hubungan Merokok Dengan Kejadian Penyakit Tuberkulosis Paru Di Wilayah Kerja Puskesmas Setu Kota Tangerang Selatan. Hal 145.

Sejati, S., Alwi, I., Sudoyo, A. W., Simadibrata, M., Setiyohadi, B., \& Syam, A. F. (2014). Buku Ajar IImu Penyakit Dalam. Jakarta: Interna Publishing. Hal 2464-72.

Shofiya, S., \& Sari, N. (2017). Hubungan Dukungan PMO dan Keteraturan Minum Obat Dengan Kegagalan Konversi TB Paru. Jurnal Keperawatan Muhamadiyah, 1(2); 48-58.

Sarwani, D., \& Nurlaela, S. (2012). Merokok dan Tuberkulosis Paru. Jurnal Kesehatan Masyarakat. Vol (4); 163.

Soetioso, V. B. (2014). Hubungan antara merokok dengan kejadian tuberkulosis paru di RSUD Dr. Soewandhie Surabaya (Doctoral dissertation, Widya Mandala Catholic University Surabaya).

Sianturi, R. (2014). Analisis faktor yang berhubungan dengan kekambuhan TB paru (studi kasus di BKPM Semarang tahun 2013). Unnes
Journal of Public Health, 3(1); 145147.

Sudoyo, Setiyohadi, Alwi, Simadibrata, Setiati. (2014). Buku Ajar Ilmu Penyakit Dalam. Jilid II Edisi VI. Jakarta: Interna Publishing. Hal. 2230-2239.

Suyanto. (2011). Metodelogi Dan Aplikasi Penelitian Keperawatan. Yogyakarta: Nuha Medika. Hal 6768.

Sudoyo, Setiyohadi, Alwi, Simadibrata, Setiati. (2014). Buku Ajar Ilmu Penyakit Dalam. Jilid I Edisi VI. Jakarta: Interna Publishing. Hal 1153-1154.

Widoyono, (2011). Penyakit Tropis Epidemiologi, Penularan,

Pencegahan

Pemberantasan. Jakarta: Erlangga Indonesia. Hal 169.

Yuniar, I., Sarwono, S., \& Astuti, S. (2017). Pengaruh PMO Dukungan Keluarga Terhadap Tingkat Kepatuhan Minum Obat TB Paru di Puskesmas Sempor 1 Kebumen URECOL. Hal 357-364.

Yoga, T. (2007). Diagnosis TB pada anak lebih sulit, Mediakom info sehat untuk Semua. Departemen Kesehatan.

Zubaidah, T., Setyaningrum, R., \& Ani, F. N. (2013). Faktor yang Mempengaruhi

Penurunanan Angka Kesembuhan TB di Kabupaten Banjar. Jurnal Buski, 4(4); 109. 